\title{
Hydroxyapatite coating on titanium endosseous implants for improved osseointegration: Physical and chemical considerations
}

\author{
Magdalena Łukaszewska-Kuska ${ }^{1, A-F}$, Piotr Krawczyk ${ }^{2, A, B, D-F}$, Agnieszka Martyla ${ }^{3, B-F}$, \\ Wiesław Hędzelek ${ }^{1, A, E, F}$, Barbara Dorocka-Bobkowska ${ }^{4, C, E, F}$ \\ ${ }^{1}$ Department of Prosthodontics, Poznan University of Medical Sciences, Poland \\ ${ }^{2}$ Institute of Chemistry and Technical Electrochemistry, Poznan University of Technology, Poland \\ ${ }^{3}$ Institute of Non-Ferrous Metals, Central Laboratory of Batteries and Cells, Poznań, Poland \\ ${ }^{4}$ Department of Oral Pathology, Poznan University of Medical Sciences, Poland \\ A - research concept and design; $\mathrm{B}$ - collection and/or assembly of data; $\mathrm{C}$ - data analysis and interpretation; \\ $\mathrm{D}$ - writing the article; $\mathrm{E}$ - critical revision of the article; $\mathrm{F}$ - final approval of the article
}

Address for correspondence

Barbara Dorocka-Bobkowska

E-mail: b.dorocka@gmail.com

Funding sources

Ministry of Science and Higher Education research project No. N403 $01032 / 0480$.

Conflict of interest

None declared

Received on August 10, 2016

Reviewed on September 13, 2016

Accepted on February 21, 2017
DOI

10.17219/acem/69084

\section{Copyright}

Copyright by Author(s)

This is an article distributed under the terms of the

Creative Commons Attribution Non-Commercial License

(http://creativecommons.org/licenses/by-nc-nd/4.0/)

\begin{abstract}
Background. For many years, hydroxyapatite (HA) has been used as a bioactive endosseous dental implant coating to improve osseointegration. As such, the coating needs to be of high purity, adequate thickness, crystalline, and of a certain roughness in order to stimulate rapid fixation and form a strong bond between the host bone and the implant. There are a number of ways of preparing the HA coating, resulting in various coating properties. Herein, we report the preparation of the HA coating using a direct electrochemical method without the need for subsequent heat treatment.
\end{abstract}

Objectives. The aim of this study was to investigate the physicochemical properties of the HP coating, deposited on titanium implants by a modified electrochemical method.

Material and methods. The coating was characterized in terms of surface chemical composition, structure, morphology, coating thickness and roughness.

Results. The coating was found to be composed of homogenous $\mathrm{HA}$ with $\mathrm{Ca} / \mathrm{P}$ and $\mathrm{Ca} / 0$ ratios of 1.62 and 0.35, respectively. No other forms of calcium phosphate were detected. The degree of crystallinity of HA was 92.4\%. The surface roughness was moderate $(S a=1.04 \mu \mathrm{m})$ with the coating thickness of $2-3 \mu \mathrm{m}$. The scanning electron microscopy (SEM) analysis revealed a uniform, integrated layer of rod-like HA crystals with the longitudinal axes parallel to the implant surface.

Conclusions. The coating reported herein was found to have potentially favorable chemical and physical characteristics fostering osseointegration.

Key words: surface properties, hydroxyapatite, electrochemical techniques, endosseous implants 


\section{Introduction}

In recent years, the number of endosseous dental implants fitted to patients has risen worldwide. The clinical success of implantation is largely dependent on implant osseointegration. In addition, the integration process is affected by a wide range of factors, such as the patient's age, gender, habits, systemic diseases, anatomical location of the implant, implant size and design, surgical procedure, implant load, and, in particular, the implant surface characteristics. ${ }^{1,2}$ Hence, the implant surface morphology and composition has been progressively modified over the years in order to optimize the bone-to-implant contact and improve osseointegration.

Hydroxyapatite $\left(\mathrm{Ca}_{10}\left(\mathrm{PO}_{4}\right)_{6}(\mathrm{OH})_{2}, \mathrm{HA}\right)$ has been used for many years as a bioactive implant coating to improve osseointegration. ${ }^{3,4}$ It has a large capacity for adsorbing proteins, it improves osteoblast proliferation, enhances bone formation and reduces bone loss. ${ }^{5-9}$ These properties induce a more rapid fixation and stronger bonding between the host bone and the implant, and are conducive to uniform bone ingrowth at the bone-implant interface. ${ }^{3,9}$ The HA coating is able to limit the formation of any fibrous membrane and convert a motion-induced fibrous membrane into a bony anchorage. ${ }^{9,10}$

The most common method of applying the HA coating onto endosseous implants is the plasma spraying technique. This method, used since the mid 1980s, requires high temperatures for the application of the HA coating. ${ }^{3}$ Despite the widespread use of this technique, there are significant concerns about the integrity of the bonding between the HA layer and the implant surface. High temperatures lead to the formation of the amorphous HA phase, which results in a higher bio-dissolution rate compared to a highly crystalline coating., ${ }^{4,5}$ The amorphous phase also causes resorption, re-absorption and degradation of the HA coating in a biological environment, which can lead to the disintegration of the coating, resulting in the reduction of both the coating-substrate bond strength and implant fixation. There is also a risk of coating delamination and disintegration with the formation of debris particles. ${ }^{10}$ Therefore, alternative HA coating processes have been extensively researched in order to avoid these undesirable effects of plasma application. One of the most promising methods is electrochemical deposition. It has many advantages: coating composition and structure can be controlled, the temperature of the process is relatively low, coating composition is homogeneous, and the coating layer is relatively thin. The formation of an irregular surface (roughness) is also an advantage. All these factors impart favorable biomedical properties to the coating.

The aim of the present work was to characterize the HA coating obtained by a modified process involving the electrochemical formation of HA on Ti screw dental implants. The physiochemical roperties of the HA coatings were characterized in terms of structural (X-ray diffraction
- XRD) and morphological (scanning electron microscopy - SEM) properties, as well as surface chemical composition (X-ray photoelectron spectroscopy - XPS), coating thickness and surface roughness.

\section{Material and methods}

\section{Electrochemical deposition}

Commercially pure Titanium class IV screw implants, $4 \mathrm{~mm}$ in diameter and $7 \mathrm{~mm}$ in length, were used (Osteoplant, Poznań, Poland). Prior to electrodeposition, the implants were sandblasted with corundum grit $\left(\mathrm{Al}_{2} \mathrm{O}_{3}\right)$ of a diameter of 53-75 $\mu \mathrm{m}$ and etched with $0.5 \mathrm{M} \mathrm{H}_{2} \mathrm{SO}_{4}$. The process of HA electrodeposition was carried out using an AUTOLAB potentiostat-galvanostat (PGSTAT 302N; Metrohm Autolab, Utrecht, the Netherlands) with a 2-electrode system in a galvanostatic mode, with a current of $5 \mathrm{~mA}$. The implant was used as the working electrode and a platinum mesh served as a counter electrode. The electrolyte consisted of $2.08 \times 10^{-4} \mathrm{M} \mathrm{CaCl}_{2}, 1.25 \times 10^{-4} \mathrm{M} \mathrm{NaH}_{2} \mathrm{PO}_{4}$ and $0.1 \mathrm{M} \mathrm{NaCl}$ in distilled water. The $\mathrm{pH}$ was adjusted to 6.3 with $\mathrm{NaOH}$ solution. The process was carried out for $105 \mathrm{~min}$ at a temperature of $100^{\circ} \mathrm{C}$. A $100 \mathrm{~mL}$ 3-neck flask was used as an electrochemical reactor and immersed in a thermostated oil bath.

\section{Physiochemical characteristics of the HA layer}

The chemical composition of the deposited coating surface was evaluated using XPS. The measurements were made using a VG Scientific photoelectron spectrometer ESCALAB-210 (VG Scientific, East Grinstead, UK) with $\mathrm{Al}$ Ka radiation $(1486.6 \mathrm{eV})$ from an X-ray source, operating at $15 \mathrm{kV}$ and $20 \mathrm{~mA}$. Survey spectra were recorded in the energy range of $0-1350 \mathrm{eV}$, with a $0.4 \mathrm{eV}$ step. High-resolution spectra were recorded with a $0.1 \mathrm{eV}$ step, $100 \mathrm{~ms}$ dwell time and $20 \mathrm{eV}$ pass energy. The 90-degree take-off angle was used in all measurements. Curve fitting was performed using the AVANTAGE software (Thermo Electron, Beverly, USA), which describes each component of the complex envelope as a Gaussian-Lorentzian sum function. A constant $0.3( \pm 0.05) \mathrm{G} / \mathrm{L}$ ratio was used and the background was fitted using a nonlinear Shirley model. Scofield sensitivity factors and a measured transmission function were used for quantification. Aromatic carbon C $1 \mathrm{~s}$ peak at $285 \mathrm{eV}$ was used as a reference for binding energy. ${ }^{11}$

The chemical composition, as well as the structural properties of the coating, were evaluated using XRD. The identification of the HA phase on Ti was performed using an XRD powder diffractometer (PW 1050; Philips, Amsterdam, the Netherlands), with $\mathrm{CuK} \alpha$ lamp radiation and a Ni filter. X-ray spectra were recorded in the angular range of $20-60^{\circ}(2 \Theta)$ with a step size of $0.020^{\circ}$ and a normalized count time of $1 \mathrm{~s} /$ step. $^{12}$ 
The degree of crystallinity $(\mathrm{Xc})$, corresponding to the fraction of the crystalline phase present in the examined volume, was evaluated by applying the equation:

$$
X_{c}=\left[1-\left(\frac{V_{112 / 300}}{I_{300}}\right)\right]
$$

where $I_{300}$ is the intensity of the (300) reflection and $V_{112 / 300}$ is the intensity of the hollow between (112) and (300) reflections, which completely disappears in non-crystalline samples. ${ }^{13}$

The surface morphology of the coating was examined with a scanning electron microscope (Tescan Vega, Pleasanton, USA).

Coating roughness was measured with an optical Wyko NT1100 profilometer (Veeco Instruments, Plainview, USA) in VSI Mode, the measured area was $0.9 \times 1.2 \mathrm{~mm}$, under $\times 20$ magnification. The Wyko Vision software v. 3.0 for NT1100 was used. The Plane Fit function was used to remove linear tilt from surface measurements. After that, the S-parameters analysis was used to assess the value of parameters. The surface roughness of the examined implants was measured at 5 random locations in the area planned to be in contact with bone.

To assess the coating thickness, the coated implants were potted in Poly/Bed 812 epoxy resin (Polysciences, Warrington, USA). The disks were then sectioned through the middle with a band saw, then ground and polished, and prepared for the SEM analysis. The coating thickness was measured at 5 locations (twice on the thread tops, twice in the thread valleys and once on the flank) using the distance measurement facility in the scanning electron microscope.

\section{Results}

The XPS analysis revealed HA to be the principal component of the electrodeposited coating. The $\mathrm{Ca} / \mathrm{P}$ and $\mathrm{Ca} / \mathrm{O}$ ratios were found to be 1.62 and 0.35 , respectively, which is in agreement with the theoretical ratio for HA (1.67 and 0.38$).{ }^{14,15}$ In addition, small amounts (up to $1 \%$ ) of F, Si, N, Na were detected as surface impurities (Fig. 1).

The XRD pattern of the HA coatings at Ti surface is shown in Fig. 2. The peaks indicated a hexagonal crystalline structure for HA. ${ }^{16}$ No other forms of calcium phosphate, such as $\mathrm{Ca}\left(\mathrm{HPO}_{4}\right)_{2} \times 2 \mathrm{H}_{2} \mathrm{O} \mathrm{Ca} 3\left(\mathrm{PO}_{4}\right)_{2}, \mathrm{Ca} 4 \mathrm{H}\left(\mathrm{PO}_{4}\right)_{3}$, were detected, indicating that the HA coating was of high purity. ${ }^{17}$

Intense reflexes from the titanium base were detected in the XRD spectrum, which overlapped with the HA peaks and may be attributed to a thin HA layer. Metallic titanium produces low-intensity HA reflexes, but does not interfere with the HA crystallinity determination.

Mineral crystallinity is the mass ratio of the measured HA crystal fraction compared to the whole mineral in the

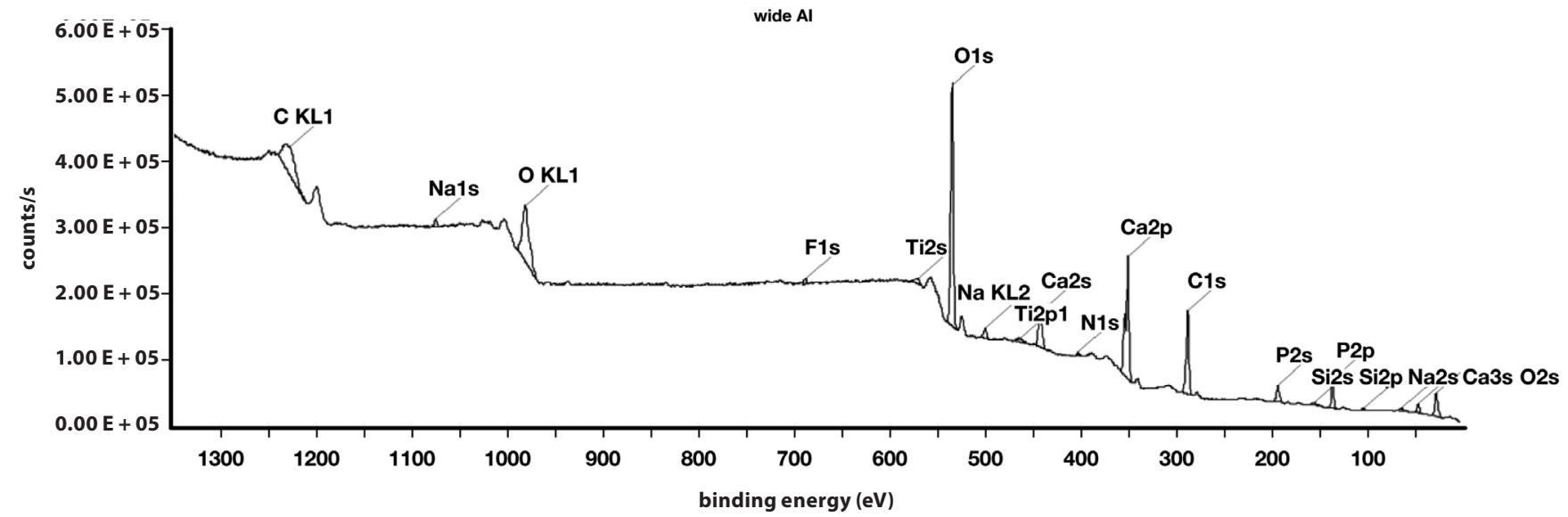

Fig. 1. XPS survey spectrum of the electrochemically deposited HA coating on a titanium implant

XPS - X-ray photoelectron spectroscopy; HA - hydroxyapatite.

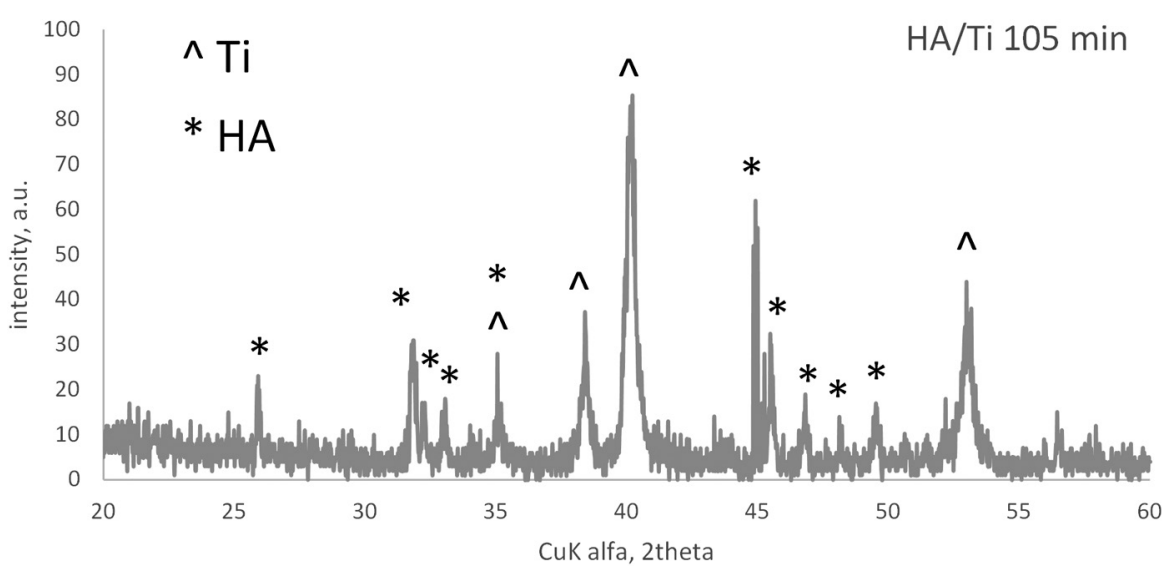

Fig. 2. XRD pattern of the HA coatings electrochemically deposited on a titanium implant

XRD - X-ray diffraction; HA - hydroxyapatite. 


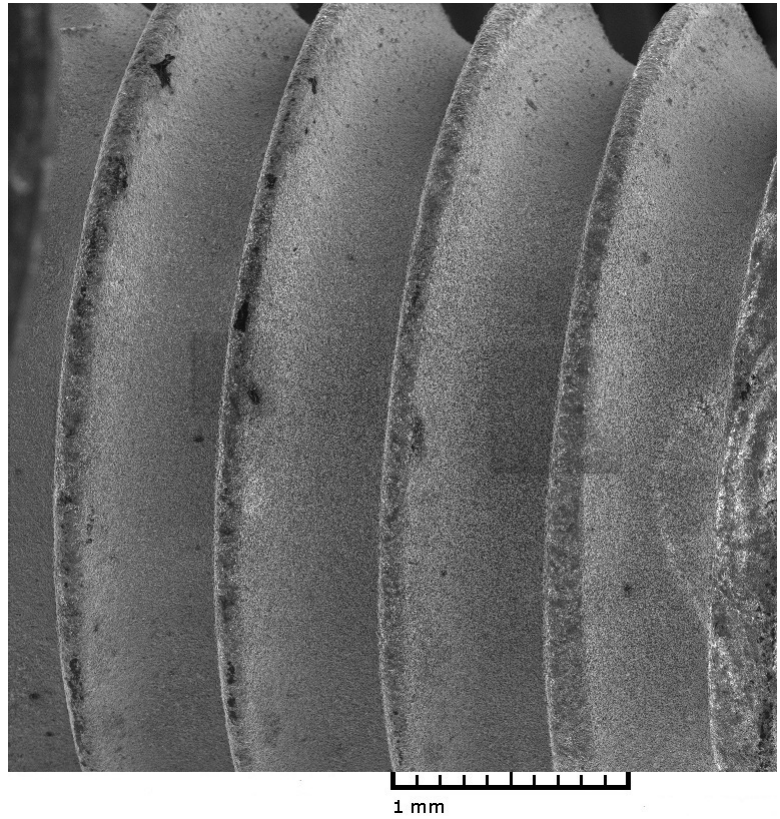

Fig. 3. SEM micrograph of the HA coating electrochemically deposited on a titanium implant thread (×66 magnification)

SEM - scanning electron microscopy; HA - hydroxyapatite.

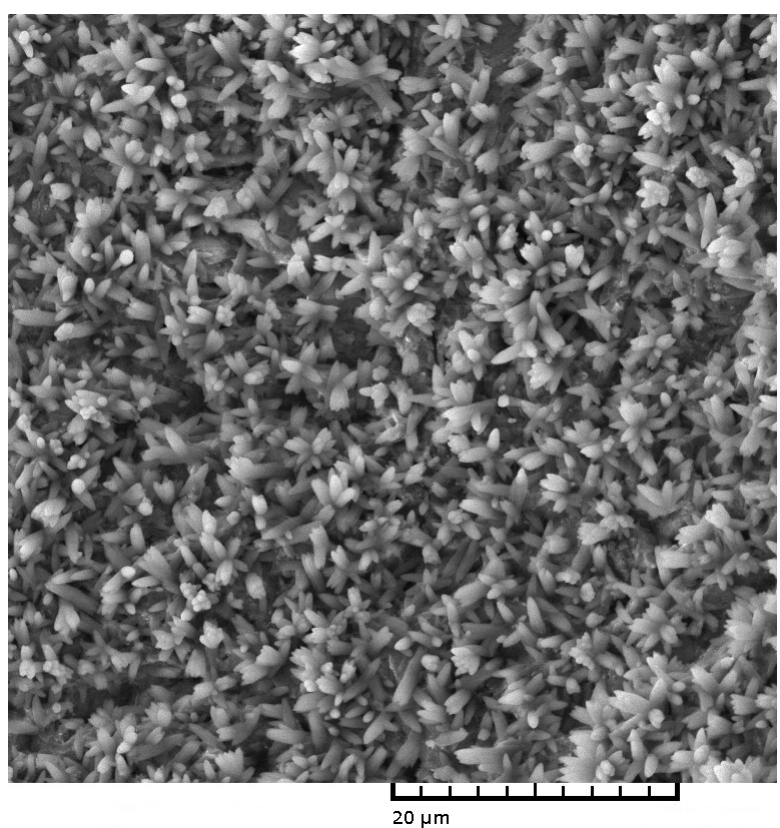

Fig. 4. SEM micrograph of the HA coating electrochemically deposited on a titanium implant ( $\times 4000$ magnification)

SEM - scanning electron microscopy; HA - hydroxyapatite.

examined sample. The higher the crystallinity, the better the mechanical properties of a material. ${ }^{18}$ The HA/Ti degree of crystallinity was found to be $92.4 \%$, which is not the highest possible value; however, the results were obtained for the HA coating on a titanium surface, as opposed to a pure powder. ${ }^{19}$

The SEM analysis revealed a uniform, integrated layer of rod-like HA crystals on the titanium surface with the longitudinal axes parallel to the implant surface (Fig. 3, 4).

Optical profilometry showed moderate surface roughness with $\mathrm{Sa}=1.04 \pm 0.12 \mu \mathrm{m}$.

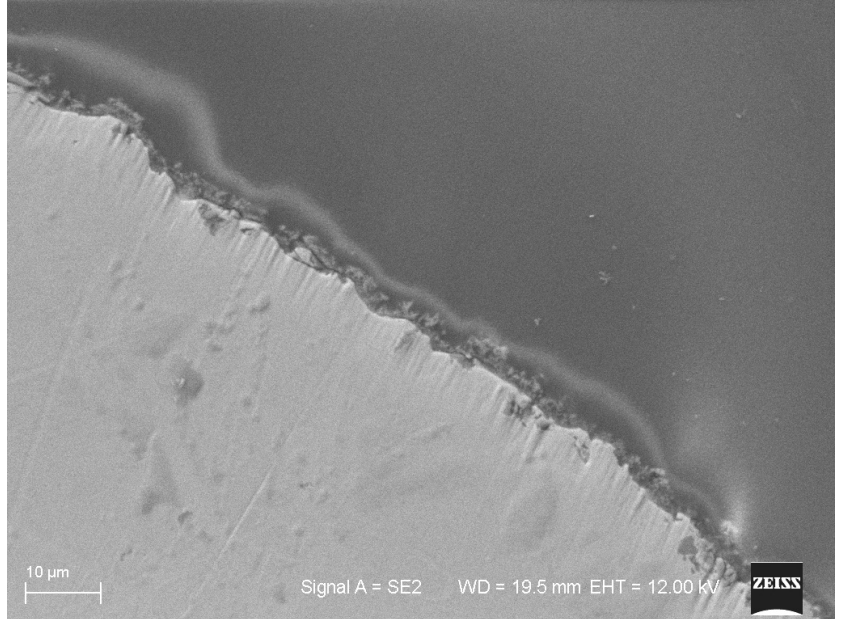

Fig. 5. Thickness of the HA coating layer observed by SEM

HA - hydroxyapatite; SEM - scanning electron microscopy.

The thickness of the HA coating layer, as observed by SEM, was within the range of $2-3 \mu \mathrm{m}$, indicating a thin and evenly formed HA layer on the corundum-blasted surface (Fig. 5).

\section{Discussion}

In this study, we presented a method of homogeneous HA coating deposition on a titanium implant surface. Like other researchers, we were able to deposit the HA coating without the presence of any other forms of $\mathrm{Ca}$ and $\mathrm{P}$ with an almost ideal $\mathrm{Ca}$ :P ratio. ${ }^{14,15,20-22}$ The coating was relatively thin and it was possible to detect reflexes from the titanium base in the XRD spectrum.

The preparation of the coating was a 1-stage procedure. The synthesis and deposition of HA was performed simultaneously in situ compared with other techniques, thus shortening and simplifying the process..$^{20,22}$

In contrast to other techniques, the sintering process was not implemented after electrochemical deposition. ${ }^{21,22} \mathrm{Sin}$ tering increases the density of the coating and eliminates the pores, but it can also bring about mechanical degradation of the titanium and decomposition, delamination and microcracking of the HA coating. ${ }^{20-22}$ Although sintering was not undertaken in our study, the coating was uniform and pore-free. High-temperature HA decomposition may also affect the biocompatibility of coatings, compromising the osseointegration of implants in bone. ${ }^{20}$

The HA/Ti crystallinity was found to be high, while the amorphous phase, which is susceptible to rapid dissolution and degradation in a biological environment, was limited to $7.6 \%{ }^{23,24}$ Thus, the potential for a reduction of both the coating-substrate bond strength and implant fixation, due to the disintegration of the coating, was significantly mitigated. ${ }^{3,5,18}$ A high coating crystallinity is also critical for the attachment of bone forming cells in the initial healing phase; it also stimulates the proliferation and differentiation of osteoblast cells. ${ }^{25,26}$ 
The SEM micrographs of the HA coating were similar in appearance to the electrodeposited and electrostatic sprayed coatings reported by other authors..$^{21,22,27}$ The advantage of such a dentate morphology on the Ti surface is that it can reduce the surface area which bears shearing strength while increasing the surface area bearing compressive strength. ${ }^{21}$

It has been reported that establishing a uniform micronthick HA layer can prevent the exfoliation of the coating layer more effectively than a thicker coating layer. ${ }^{25,26,28,29}$ The SEM measurements in the present study confirmed that the specimens had a uniform HA coating thicknesses $(2-3 \mu \mathrm{m})$. Thus, it can be assumed that the HA coating technique employed in the present study provides resistance to delamination. However, future studies should include tensile strength testing in order to test the bond strength between the coating layer and the titanium implant surface. A uniform, micron-thick coating layer could also maintain the original microtexture of the sandblasted implant surface, which has a proven potential for osseointegration. ${ }^{30}$

To improve the bonding strength between HA and titanium implants, the surface of a Ti screw was etched with $\mathrm{H}_{2} \mathrm{SO}_{4}$ before electrodeposition. Etching produces small pits on the titanium surface, which act as a thin scaffold between the HA coating and Ti substrate. Thus, the HA coating is able to endure greater compressive loads compared to tensile and shear loads. ${ }^{21}$

According to Wennerberg et al., optimal surfaces for intense bone reaction require a moderate surface roughness $(\mathrm{Sa}=1-2 \mu \mathrm{m}) .{ }^{30}$ A review of over 100 publications showed that such surfaces facilitate better bone reaction than smooth $(\mathrm{Sa}<0.5 \mu \mathrm{m})$ or minimally rough (Sa $0.5-1 \mu \mathrm{m})$ surface implants, or some implants with rough surfaces $(\mathrm{Sa}>2 \mu \mathrm{m})$.

\section{Conclusions}

Using a modified electrochemical deposition method, the HA coating was deposited on pure titanium implant surfaces during a 105-minute electrodeposition process. The obtained coating was found to be highly pure, homogenous HA, which was uniform, crack-free and thin. Moreover, its moderate surface roughness and coating crystallinity was potentially conducive to tissue reaction.

\section{References}

1. Jokstad A, Braegger U, Brunski JB, Carr AB, Naert I, Wennerberg A Quality of dental implants. Int Dent J. 2003:53,409-443.

2. Albrektsson T, Branemark PI, Hansson HA, Lindstrom J. Osseointegrated titanium implants: Requirements for ensuring a longlasting, direct bone-to-implant anchorage in man. Acta Orthop Scand. 1981;52:155-170.

3. Narayanan R, Seshadri SK, Kwon TY, Kim KH. Calcium phosphatebased coatings on titanium and its alloys. J Biomed Mater Res Part B: Appl Biomater. 2008;85B:279-299.

4. Yang Y, Dennison D, Ong JL. Protein adsorption and osteoblast precursor cell attachment to hydroxyapatite of different crystallinities. Int J Oral Maxillofac Implants. 2005;20:187-192.
5. O'Hare P, Meenan BJ, Burke GA, Byrne G, Dowling D, Hunt JA. Biological responses to hydroxyapatite surfaces deposited via a co-incident microblasting technique. Biomaterials. 2010;3:515-522.

6. Wang C, Karlis GA, Anderson Gl, et al. Bone growth is enhanced by novel bioceramic coatings on Ti alloy implants. J Biomed Mater Res $A$. 2009;90:419-428.

7. Le Guéhennec L, Soueidan A, Layrolle P, Amouriq Y. Surface treatments of titanium dental implants for rapid osseointegration. Dent Mater. 2007;23:844-854.

8. Shen JW, Wu T, Wang Q, Pan HH. Molecular simulation of protein adsorption and desorption on hydroxyapatite surfaces. Biomaterials. 2008;29:513-532.

9. Kilpadi KL, Chang PL, Bellis SL. Hydroxylapatite binds more serum proteins, purified integrins and osteoblast precursor cells than titanium or steel. J Biomed Mater Res. 2001;57:258-267.

10. Sun L, Berndt CC, Gross KA, Kucuk A. Material fundamentals and clinical performance of plasma-sprayed hydroxyapatite coatings: A review. J Biomed Mater Res B Appl Biomater. 2001;58:570-592.

11. Beamson G, Briggs D. High Resolution XPS of Organic Polymers. The Scienta ESCA300 Database. Chichester: John Wiley \& Sons; 1992.

12. Jenkins R, Snyder RL. Introduction to X-Ray Powder Diffractomerty. New York, NY: John Wiley \& Sons; 1996.

13. Stötzel C, Müller FA, Reinert F, Niederdraenk F, Barralet JE, Gbureck U. Ion adsorption behaviour of hydroxyapatite with different crystallinities. Colloids Surf B Biointerfaces. 2009;74:91-95.

14. Milella E, Cosentino F, Licciulli A, Massaro C. Preparation and characterisation of titania/hydroxyapatite composite coatings obtained by sol-gel process. Biomaterials. 2001;22:1425-1431.

15. Zhu X, Eibl O, Scheideler L, Geis-Gerstorfer J. Characterization of nano hydroxyapatite/collagen surfaces and cellular behaviors. J Biomed Mater Res A. 2006;79:114-127.

16. Hanawalt JD, Rinn HW, Frevel LK. Chemical analysis by X-ray diffraction. Anal Chem. 1938;10:457-512.

17. Saremi M, Mottaghi Golshan B. Electrodeposition of nano size hydroxyapatite coating on Ti alloy. IJMSE. 2006;3:1-5.

18. Ostrowski K, Dziedzic-Gocławska A, Stachowicz W, Michalik J. Radiation-induced paramagnetic centres in research on bone physiology. Clin Orthop Relat Res. 1991;272:21-29.

19. Landi W, Tampieri A, Celotti G, Sprio S. Densification behaviour and mechanisms of synthetic hydroxyapatites. J Eur Ceram Soc. 2000;20:2377-2387.

20. Hu R, Lin CJ, Shi HY. A novel ordered nano hydroxyapatite coating electrochemically deposited on titanium substrate. J Biomed Mater Res A. 2007;80:687-692.

21. Chen F, Lam WM, Lin CJ, et al. Biocompatibility of electrophoretical deposition of nanostructured hydroxyapatite coating on roughen titanium surface: In vitro evaluation using mesenchymal stem cells. J Biomed Mater Res B Appl Biomater. 2007;82:183-191.

22. Lin C, Han H, Zhang F, Li A. Electrophoretic deposition of HA/MWNTs composite coating for biomaterial applications. JMater SciMater Med. 2008;19:2569-2574.

23. Burke EM, Lucas LC. Dissolution kinetics of calcium phosphate coatings. Implant Dent. 1998;7:323-330.

24. Eanes ED. Amorphous calcium phosphate. Oral Sci. 2001;18:130-147.

25. Yang Y, Bumgardner JD, Cavin R, Carnes DL, Ong JL. Osteoblast precursor cell attachment on heat-treated calcium phosphate coatings. J Dent Res. 2003;82:449-453.

26. Jung UW, Hwang JW, Choi DY, et al. Surface characteristics of a novel hydroxyapatite-coated dental implant. J Periodontal Implant Sci. 2012; 42:59-63.

27. Huang J, Jayasinghe SN, Best SM, et al. Novel deposition of nanosized silicone substituted hydroxyapatite by electrostatic spraying. J Mater Sci Mater Med. 2005;16:1137-1142.

28. Katto M, Ishibashi K, Kurosawa K, et al. Crystallized hydroxyapatite coatings deposited by PLD with targets of different densities. J Phys Conf Ser. 2007;59:75-78.

29. Cleries L, Fernandez-Pradas JM, Sardin G, Morenza JL. Dissolution behaviour of calcium phosphate coatings obtained by laser ablation. Biomaterials. 1998;19:1483-1487.

30. Wennerberg A, Albrektson T. Effects of titanium surface topography on bone integration: A systematic review. Clin Oral Implants Res. 2009;20:172-184. 